\title{
The effects of beating, web forming and sizing on the surface energy of Eucalyptus globulus kraft fibres evaluated by inverse gas chromatography
}

\author{
M.G. Carvalho ${ }^{1, *}$, J.M.R.C.A. Santos ${ }^{2}$, A.A. Martins ${ }^{3}$ and M.M. Figueiredo ${ }^{1}$ \\ ${ }^{1}$ Department of Chemical Engineering, University of Coimbra, Pinhal de Marrocos, 3030-290 Coimbra, \\ Portugal; ${ }^{2}$ Department of Chemical Technology, Polytechnic Institute of Braganca, Campus de Santa \\ Apolónia, 5301-857 Braganç, Portugal; ${ }^{3}$ RAIZ-Forest and Paper Research Institute, 3801-501 Eixo, Aveiro, \\ Portugal; *Author for correspondence, e-mail: mgc@eq.uc.pt
}

Received 7 April 2004; accepted in revised form 13 December 2004

Key words: Eucalyptus globulus, IGC, Kraft pulps, Paper properties, Surface energy

\begin{abstract}
In this work attention has been focused on the effects of papermaking beating, web forming and sizing operations on the physical/chemical surface properties of bleached Eucalyptus globulus kraft fibres. Inverse gas chromatography (IGC) was used to determine the dispersive component of surface tension $\left(\gamma_{\mathrm{s}}{ }^{\mathrm{d}}\right)$ as well as the acidic/basic character (according to the Lewis concept) of the solid surfaces (pulp fibres and pulp handsheets). The results have shown that the main effect of beating is to increase the fibre's Lewis acidic character. Web forming caused a strong decrease in $\gamma_{\mathrm{s}}{ }^{\mathrm{d}}$ and significant increments in the adhesion works of both acidic and basic probes, lowering the ratio between the two. Nevertheless, the surface of handsheets still exhibited a dominant acidic character. The sizing operation did not change the dispersive component of the surface tension significantly but decreased the difference between the adhesion works of the acidic and basic probes, rendering the handsheet surface less Lewis acidic and more Lewis basic. Thus, although internal sizing is expected to strongly influence liquid spreading at the paper surface and liquid penetration of the fibre's network, it is concluded that beating and web forming lead to important changes in the surface energetic properties of the Eucalyptus globulus kraft fibres.
\end{abstract}

Abbreviations: $A$ - molecular surface area of the probes used in the IGC study; Acet - acetone; $A N^{*}-$ Gutmann's modified acceptor number; $\mathrm{CHCl}_{3}$ - trichloromethane; DCM - dichloromethane; $D N$ - Gutmann's donor number; EtAcet - ethyl acetate; $F$ - carrier gas flow rate (measured with a digital flow meter); GC - gas chromatography; IGC - inverse gas chromatography; $J$ - correction factor for gas compressibility; $K_{\mathrm{a}}$ - surface Lewis acidity; $K_{\mathrm{b}}$ - surface Lewis basicity; $N$ - Avogadro's constant; $R$ - ideal gas law constant; $T$ - temperature in Kelvin; $t_{0}$ - retention time of the non-interacting molecule; $t_{\mathrm{r}}$ - retention time of the probe molecule; THF - tetrahydrofuran; $V_{\mathrm{n}}$ - net retention volume; $\Delta G$ - free energy of adsorption of the probe on the stationary phase surface; $\Delta G^{d}$ - dispersive component of the free energy of adsorption; $\Delta G^{s}$ - specific component of the free energy of adsorption; $\Delta H^{s}$ - enthalpy of adsorption; $\Delta S^{s}$ - entropy of adsorption; $\gamma_{1}^{\mathrm{d}}$ - dispersive component of the surface free energy of the liquid; $\gamma_{\mathrm{s}}^{\mathrm{d}}$ - dispersive component of the surface free energy of the solid; $\gamma_{\mathrm{s}}^{\mathrm{p}}$ - polar component of the surface free energy of the solid; $W_{\mathrm{a}}^{\mathrm{s}}-$ specific component of the adhesion work between the polar probes and the stationary phase 


\section{Introduction}

Eucalypt fibres are being used worldwide to produce the highest quality printing and writing paper grades. This is due, firstly, to the characteristics of the eucalypt fibre itself. Compared to the most commonly used hardwood fibres, in general eucalypt fibres exhibit lower fibre length and width but similar wall thickness, which leads to a higher number of fibres per unit mass and a unique combination of stiffness and conformability capacity upon beating. These features provide the paper with high opacity, high bulk, excellent formation, excellent surface smoothness and enough strength, for good runability and superior end usage performance. However, it is well known that the specific conditions of pulp production (cooking and bleaching) affect the internal and the surface chemical composition of the fibres, which is of consequence to the surface, structural, optical and strength properties of the papersheet. Furthermore, the papermaking operations of beating, web forming and sizing play an important role in the final quality of the paper. The beating operation (a mechanical process in which fibres undergo high shear and compression forces in the presence of water) aims at improving bonding properties, which decreases the pulp drainability, the paper porosity and optical properties and increases the paper mechanical resistance. Furthermore, in order to enhance paper resistance to liquid penetration, chemical sizers like AKD (alkyl ketene dimer) are added to the stock.

Among other factors, differences in the surface energy determine changes in the surface adhesive properties and spreading of liquids (like inks) as well as changes in their penetration into the fibres network. Since the fibre surface properties can influence the final product quality, it is not surprising that a large amount of research work is being carried out on the study of the surface energetic characteristics of papermaking cellulose fibres and the interaction of these surfaces with other systems, such as printing inks (Banerjee 1991; Santos et al. 2001). Adhesion between these systems is directly related to their capability to interact by means of dispersive and acid-base intermolecular interactions. Therefore, the characterisation of these phenomena is of major importance.
In what concerns eucalypt fibres, studies have been undertaken to investigate the effects of cooking and bleaching conditions on the surface and strength properties of the corresponding kraft pulps (Shen and Parker 1999; Aquino et al. 2002). The study of Aquino et al. (2002) on Eucalyptus globulus kraft fibres has revealed that these properties are highly dependent on the history of the cooking and bleaching processes. For instance, high cooking temperatures strongly decrease the fibre surface free energy and the introduction of an oxygen delignification stage prior to bleaching enhances the Lewis acidic character of the fibres. However, the effect of subsequent papermaking operations, like beating and web forming, on the fibre's surface energy properties is not yet well known.With regard to the effects of AKD sizing, the work of Shen et al. (1998) and that of Lee and Luner (1989) are worth mentioning.

The purpose of the present study is to examine changes in the surface energy of fibres due to beating and sizing operations. Comparisons are also made between fibre surface free energy of pulp and of handsheets in order to investigate the effects of fibre bonding and collapse, and migration of fines that occur at the web formation stage. The present work is part of a more extensive work whose main objective is to study the relationship between chemical and physical properties of fibres and fibre networks and the functional properties of the paper, in order to assess the contribution of these relationships to the printing performance of office papers.

The growing awareness of the importance of solid surfaces, interfaces and interphases in determining the useful properties of polymeric systems, has led to the development of inverse gas chromatography (IGC) as a useful technique in evaluating the potential for interaction of different components of polymer blends, composites, and multicomponent polymeric systems in general. The first papers on IGC go back 32 years. Since then, and in particular since 1990, the number of publications per year has increased exponentially. Data obtained from IGC experiments may, in favourable cases, correlate directly with observed performance criteria, such as colour development, gloss, rheological properties, adhesion and mechanical properties (Lee 1991; Mukhopadhyay and Schreiber 1993; Schultz and Lavielle 1989). 
Moreover, IGC has been increasingly used to characterize the surface thermodynamic properties of many inorganic and organic materials, like polymers, pigments, coatings, wood meal, wood pulp, paper, etc. (Al Saigh 1994; Papirer and Balard 1999; Santos et al. 2001; 2002a,b). More information on theoretical and practical aspects of this technique can be found in reviews such as that of Papirer and Balard (1999) and that of Al Saigh (1994).

The IGC technique enables the evaluation of several surface energy related parameters, namely the dispersive component of the surface tension, arising from London and Van-der-Waals forces, and the acid/base character according to the Lewis concept (i.e., ability to accept and donate electrons). IGC is very similar to conventional gas chromatography (GC), the main difference being the fact that the material under study is the stationary phase introduced into the chromatographic column, whereas the compounds injected (probes) have well-known properties. As mentioned above, in this work, the packed materials under investigation are pulp and pulp handsheets.

\section{Materials and methods}

\section{Sample preparation}

Eucalyptus globulus pulp was produced in a 71 laboratory MK digester (model 409 MII from M/ K Systems, Inc.) by the kraft process. The cooking conditions were $160{ }^{\circ} \mathrm{C}$ cooking temperature during $45 \mathrm{~min}, 1{ }^{\circ} \mathrm{C} / \mathrm{min}$ heating rate, a liquor to wood ratio of $4,16 \%$ active alkali charge, as $\mathrm{Na}_{2} \mathrm{O}$, and $30 \%$ sulphidity, resulting in a kappa number of 14.8. The pulp was then bleached by applying a DEDED sequence to achieve a brightness of $90 \%$ ISO (sample A). In order to analyse the changes on the surface free energy due to the beating process, a portion of the bleached pulp was beaten in a laboratory PFI mill to achieve 30 Schopper Riegler (sample B). To study the influence of sheet formation and sizing on the surface characteristics of fibres, handsheets were made (according to ISO 5269/1-1979) using the beaten pulp with and without the sizing agent $\mathrm{AKD}$, samples $\mathrm{D}$ and $\mathrm{C}$, respectively. The sizing agent emulsion (with $13.5 \%$ active component supplied by RAISIO Chemicals Ltd.) was added to the pulp suspension after addition of sodium hydrogen carbonate $(0.1 \%)$, which is the reaction catalyst. After strong mixing, laboratory round sheets were formed and subjected to drying (for AKD curing) during $10 \mathrm{~min}$ at $80^{\circ} \mathrm{C}$. The AKD amount was adjusted to obtain $180 \mathrm{~s}$ HST (Hercules Sizing Test) level. Table 1 summarises the characteristics of the several samples tested.

\section{Inverse gas chromatography}

A Perkin Elmer 8410 gas chromatograph equipped with a hydrogen flame ionization detector (FID) was used for IGC data collection. The instrument was connected to a Kompensograph Siemens integrator. Stainless steel columns, $0.5 \mathrm{~m}$ long and $0.4 \mathrm{~mm}$ ID, were degreased, washed and dried before packing. In order to reduce the particles size, samples A and B were milled and samples C and $\mathrm{D}$ were cut into small pieces (about $2 \mathrm{~mm} \times 2 \mathrm{~mm}$ ). On average, approximately $1.3 \mathrm{~g}$ of milled pulp and $2 \mathrm{~g}$ of handsheet pieces were packed into the GC columns using a vacuum pump. The packed columns were conditioned overnight at $105{ }^{\circ} \mathrm{C}$ under a helium flow before any measurements were made. This procedure aims to remove any volatiles, including water molecules, that may be adsorbed at the stationary phase surface and that, consequently, could affect the retention of the probe molecules. As all the columns are subject to the same pre-treatment conditions, this procedure is not expected to

Table 1. Summary of sample characteristics.

\begin{tabular}{lllll}
\hline & Sample A & Sample B & Sample C & Sample D \\
\hline Sample type & Pulp & Pulp & Handsheet & Handsheet \\
PFI rpm to 30 SR & & 1200 & 1200 & 1200 \\
Grammage $\left(\mathrm{g} / \mathrm{m}^{2}\right)$ & & 80 & 80 \\
Sizing $(\mathrm{mg} \mathrm{AKD} / 10 \mathrm{~g}$ of pulp) & & & 75 \\
\hline
\end{tabular}


contribute to the observed differences in the surface energy of the samples analysed.

Experiments were carried out at column temperatures between 40 and $60{ }^{\circ} \mathrm{C}$, at $5{ }^{\circ} \mathrm{C}$ intervals, in order to evaluate the variation of $\gamma_{\mathrm{s}}{ }^{\mathrm{d}}$ with temperature as well as the enthalpies of adsorption for the polar probes. The injector and detector were kept at 180 and $200{ }^{\circ} \mathrm{C}$, respectively. Helium was used as carrier gas and its flow was selected to ensure that neither absorption nor diffusion of the probes would occur inside the column stationary phase. Minute quantities of probe vapour $(<1 \mu \mathrm{l})$ were injected into the carrier gas flow to ensure that the experiments took place at infinite dilution. The probes were of chromatographic grade and used as received (Sigma-Aldrich Ltd.). Their relevant properties are listed in Table 2. The results reported for the work of adhesion of acidic and basic probes were estimated from the retention times obtained for tetrahydrofuran (basic probe) and chloroform (acidic probe). Replicated measurements were performed with two columns prepared in the same way. Retention times were the average of at least five injections. Reproducibility between runs was always better than $2 \%$. The retention times were determined graphically according to the Conder and Young method (Kamdem and Riedl 1992).

Natural gas with $83.7 \%$ methane was used to determine the dead retention volume. It was ensured that no extraneous peaks were obtained due to the use of natural gas, the methane peak being clearly identified, and peaks relating to other components being not significant (as expected, as the runs were carried out under infinite dilution conditions).

\section{IGC data analysis}

IGC data processing was carried out according to customary methods, well described in the literature (see for instance Chtourou et al. (1995)). In IGC, an inert carrier gas elutes a minute quantity of a probe molecule through a column packed with the material under study. Due to the interactions between the two phases, the probe molecules are retained for a certain time, $t_{\mathrm{r}}$, which is used to calculate the net retention volume, $V_{\mathrm{n}}$, according to Eq. (1):

$$
V_{\mathrm{n}}=\left(t_{\mathrm{r}}-t_{0}\right) F \cdot J
$$

Here $t_{0}$ is the dead retention time of the marker probe, $F$ is the carrier gas flow rate (measured with a digital flow meter) and $J$ is the correction factor for gas compressibility (Belgacem et al. 1995).

\section{Determination of the dispersive component of surface tension}

Assuming that experiments take place at infinite dilution, the free energy of adsorption of the probe on the stationary phase surface per mole, $\Delta G$, can be determined from the retention volume, $V_{\mathrm{n}}$, according to

$$
\Delta G=-R T \ln \left(V_{\mathrm{n}}\right)+C_{1} .
$$

Here $R$ is the ideal gas constant, $T$ is the absolute column temperature and $C_{1}$ is a constant that depends upon the chromatographic column and the reference state (Dorris and Gray 1980). Considering that the dispersive and specific components, respectively $\Delta G^{d}$ and $\Delta G^{s}$, are additive, as suggested by Fowkes (1987), Eq. (2) can be rewritten as

$$
\Delta G^{\mathrm{d}}+\Delta G^{\mathrm{s}}=-R T \ln \left(V_{\mathrm{n}}\right)+C_{1} .
$$

On the other hand, the free energy of adsorption can be related to adhesion work, $W_{\mathrm{a}}$ (Dorris and Gray 1980), according to

$$
-\Delta G=N \cdot A \cdot W_{\mathrm{a}} .
$$

Here $N$ is Avogadro's number and $A$ the crosssectional area of the probe to be tested (Table 2). If non-polar components (such as $n$-alkanes) are

Table 2. Characteristics of IGC probes (Kamdem et al. 1993; Santos et al. 2001).

\begin{tabular}{llllllll}
\hline Polar probes & $A\left(\AA^{2}\right)$ & $\gamma_{1}^{\mathrm{d}}\left(\mathrm{mJ} / \mathrm{m}^{2}\right)$ & $A N^{\mathrm{a}}(\mathrm{kJ} / \mathrm{mol})$ & $D N(\mathrm{~kJ} / \mathrm{mol})$ & Alkanes & $A\left(\AA^{2}\right)$ & $\gamma_{1}^{\mathrm{d}}\left(\mathrm{mJ} / \mathrm{m}^{2}\right)$ \\
\hline $\mathrm{CHCl}_{3}{ }^{\mathrm{a}}$ & 44.0 & 25.0 & 22.6 & - & $\mathrm{C}_{6} \mathrm{H}_{14}$ & 51.4 & 18.4 \\
$\mathrm{DCM}^{\mathrm{a}}$ & 31.5 & 27.6 & 16.3 & - & $\mathrm{C}_{7} \mathrm{H}_{16}$ & 57.0 & 20.3 \\
$\mathrm{THF}^{\mathrm{a}}$ & 45.0 & 22.5 & 2.1 & 84.2 & $\mathrm{C}_{8} \mathrm{H}_{18}$ & 62.8 & 21.3 \\
EtAcet $^{\mathrm{a}}$ & 48.0 & 19.6 & 6.3 & 71.7 & $\mathrm{C}_{9} \mathrm{H}_{20}$ & 68.9 & 22.7 \\
& & & & & $\mathrm{C}_{10} \mathrm{H}_{22}$ & 75.0 & 23.9 \\
\hline
\end{tabular}

${ }^{\text {a }}$ Please consult the list of abbreviations. 
used, only dispersive interactions occur and the adhesion work is given by

$$
W_{\mathrm{a}}=2\left(\gamma_{\mathrm{s}}^{\mathrm{d}} \gamma_{1}^{\mathrm{d}}\right)^{1 / 2}
$$

Here $\gamma_{\mathrm{s}}^{\mathrm{d}}$ and $\gamma_{1}^{\mathrm{d}}$ are the dispersive components of the surface tension of the solid (stationary phase) and of the liquid, respectively.

Replacing Eqs. (4) and (5) in Eq. (2) leads to

$$
2 N\left(\gamma_{\mathrm{s}}^{\mathrm{d}}\right)^{1 / 2} A\left(\gamma_{1}^{\mathrm{d}}\right)^{1 / 2}+C=R T \ln \left(V_{\mathrm{n}}\right)
$$

The slope of the straight line, referred to as the reference line, obtained by plotting $R T \ln \left(V_{\mathrm{n}}\right)$ vs. $2 N\left(\gamma_{1}^{\mathrm{d}}\right)^{1 / 2} A$, for a homologous $n$-alkane series (Figure 1(a)), leads to the determination of $\gamma_{s}{ }^{d}$ for a given temperature.

\section{Determination of the surface acid-base properties}

Acid-base characteristics of fibre surface are determined by analysing the interaction of the polar probes with the solid surface and quantifying the deviation from the reference line, leading to the estimation of the specific free energy, $\Delta G^{s}$, as

$$
-\Delta G^{\mathrm{s}}=R T \ln \left(V_{\mathrm{n}}\right)-R T \ln \left(V_{\mathrm{n}, \mathrm{ref}}\right) .
$$

Here $V_{\mathrm{n}, \text { ref }}$ is the retention volume established by the $n$-alkanes reference line (Eq. (1)), $V_{\mathrm{n}}$ being now the retention volume of the polar probes. This calculation is also illustrated in Figure 1(a).

The adhesion work between the polar probes tested and the fibres, $W_{\mathrm{a}}^{\mathrm{s}}$, can be evaluated from the specific free energy, given by Eq. (7), as

$$
W_{\mathrm{a}}^{\varsigma}=\frac{R T}{N \cdot A} \ln \left(\frac{V_{\mathrm{n}}}{V_{\mathrm{n}, \mathrm{ref}}}\right) .
$$

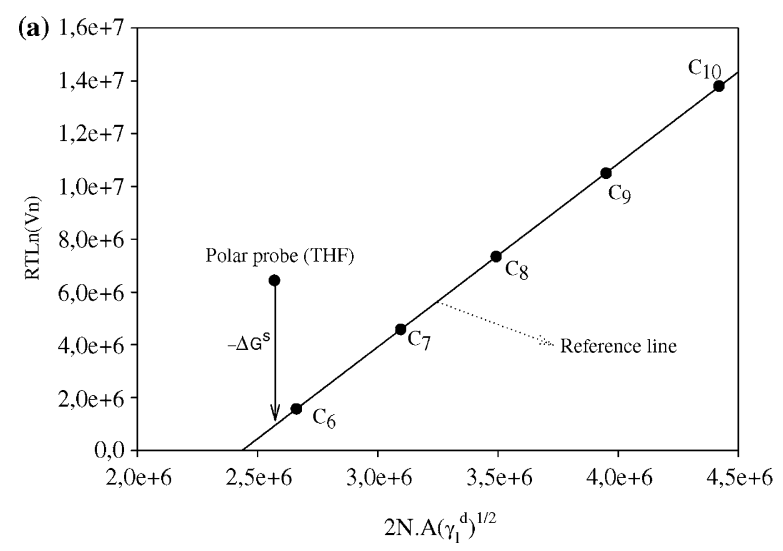

By carrying out experiments at different temperatures, it is possible to determine the enthalpy and entropy of adsorption, respectively $\Delta H^{s}$ and $\Delta S^{s}$, from the plots of $\Delta G^{s} / T$ vs. $1 / T$, according to the following equation:

$$
\frac{\Delta G^{\mathrm{s}}}{T}=\frac{\Delta H^{\mathrm{s}}}{T}-\Delta S^{\mathrm{s}} .
$$

The acidic and basic constants, $K_{\mathrm{a}}$ and $K_{\mathrm{b}}$, respectively, are calculated using Eq. (10) from the linear relationship $\Delta H^{s} / A N^{*}$ vs. $D N / A N^{*}$ for the series of polar probes tested, characterized by different $A N^{*}$ (modified acceptor) and $D N$ (donor) numbers (Table 2). The procedure is illustrated in Figure 1(b).

$$
\frac{\left(-\Delta H^{\mathrm{s}}\right)}{A N^{*}}=K_{\mathrm{a}} \frac{D N}{A N^{*}}+K_{\mathrm{b}} .
$$

The retention times obtained from the IGC experiments are converted in net retention volumes, according to Eq. (1). For subsequent data reduction the net retention volume can be normalized by using the stationary phase surface area or mass (the latter being the rule). In any case, and bearing in mind the data reduction mathematical procedures, it should be noted that the normalization of the net retention volume, using either the stationary phase mass or surface area, does not influence the values of $\gamma_{\mathrm{s}}{ }^{\mathrm{d}}$ or its variation with temperature $\left(\mathrm{d} \gamma_{\mathrm{s}}{ }^{\mathrm{d}} / \mathrm{d} T\right)$, nor the values of $W_{\mathrm{a}}^{\mathrm{s}}, \Delta H^{s}$, $K_{\mathrm{a}}$ and $K_{\mathrm{b}}$.

The limitations of the IGC are well described in the literature, and have actually been the subject of discussion in a paper published by one of the authors (Santos et al. 2002a). The best

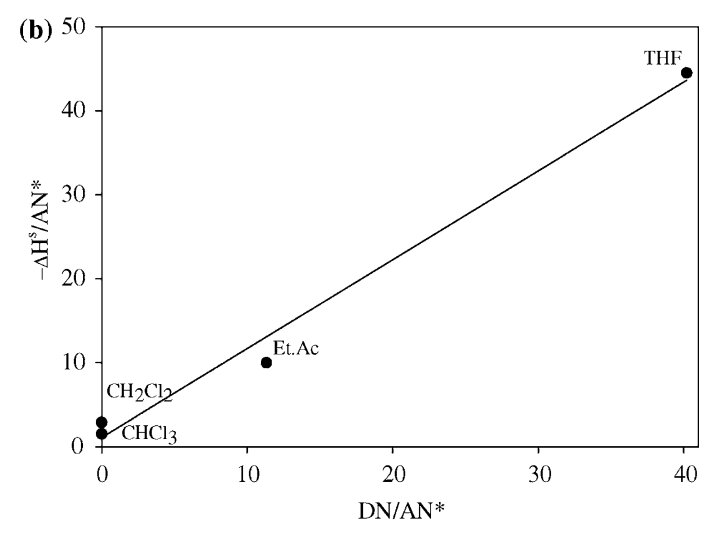

Figure 1. Determination of (a) $\gamma_{\mathrm{s}}^{\mathrm{d}}$ (Eq. (6)) and $\Delta G^{\mathrm{s}}$ (Eq. (7)) for the basic probe THF, and (b) acidic and basic constants (Eq. (10)) for sample C. 
approach to assess the surface energetic properties (surface tension, surface Lewis acidic/basic properties) of a material by IGC is the side-byside analysis of the energy of adsorption, enthalpy of adsorption and surface Lewis acidity and basicity constants. This procedure allows for a coherent and systematic interpretation of the IGC results, leading to a more complete analysis than the sole analysis of the semi-empirical values of $K_{\mathrm{a}}$ and $K_{\mathrm{b}}$. This was the procedure adopted in the present paper.

\section{BET surface area determination}

The BET specific surface area of the IGC column stationary phases was determined by nitrogen adsorption in a Micromeritics ASAP 2000 unit.

\section{SEM imaging}

SEM images of the IGC column stationary phases were obtained in a JEOL JSM-5310 unit, using an accelerating voltage of $10 \mathrm{kV}$.

\section{FTIR analysis}

FTIR spectra of the IGC column stationary phases was carried out in a Nicolet Magma IR TM750 unit (ATR MKII Golden Gate).

\section{Contact angle measurement}

An OCA20 Dataphysics unit was used for the determination of static contact angles relating to the handsheets. The liquids used were water, formamide, diodomethane, ethylene glycol and propylene glycol. The values of contact angle were processed according to the Owens, Wendt, Rabel and Kaelble approach (OWRK method).

\section{Results and discussion}

\section{BET surface area determination}

In Table 3 are summarised the results concerning the determination of the specific surface area of the IGC column stationary phases.
Table 3. BET surface area $\left(\mathrm{m}^{2} / \mathrm{g}\right)$ of the IGC columns stationary phases.

\begin{tabular}{llll}
\hline Sample A & Sample B & Sample C & Sample D \\
\hline $1.621 \pm 0.014$ & $1.961 \pm 0.036$ & $1.388 \pm 0.016$ & $0.991 \pm 0.029$ \\
\hline
\end{tabular}

In Table 3 it can be observed that the beating process applied to pulp A (production of sample B) increases the specific surface area due to the more open structure and the production of fibrils along the fibre's surface. Moreover, the specific surface area of the handsheet stationary phases (samples $\mathrm{C}$ and $\mathrm{D}$ ) is lower than that of the pulp samples (A and $\mathrm{B}$ ), as expected. The stationary phase corresponding to the sized handsheet (sample D) has a lower specific surface area than that of the non-sized handsheet (sample C). This may be due to reduction in porosity caused by covalent bonding between the AKD molecules and the fibres and fines surface.

\section{SEM imaging}

SEM images of the IGC columns stationary phases are presented in Figures 2-5, concerning samples $\mathrm{A}, \mathrm{B}, \mathrm{C}$ and $\mathrm{D}$, respectively.

As mentioned, samples A and B consist of milled pulp. The milling operation aimed at reducing the size of pulp flocks so that the IGC column stationary phase could be packed. It can be observed in Figures 2 and 3 that the effects of this procedure do not dominate over the effect of the PFI beating process (which results in a more open structure and the production of fibrils along the fibre's surface). This is further supported by the fact that even after the milling procedure sample B has a greater surface area than sample A (Table 3). The consequences of the pulp milling, if this operation had been extended, would be increased exposure of the cross sectional surface and lumen surface in addition to the detachment of fibre wall fragments. Consequently, the thermodynamic properties $\left(\gamma_{\mathrm{s}}{ }^{\mathrm{d}}, \mathrm{d} \gamma_{\mathrm{s}}{ }^{\mathrm{d}} /\right.$ $\mathrm{d} T, W_{\mathrm{a}}(\mathrm{THF}), W_{\mathrm{a}}\left(\mathrm{CHCl}_{3}\right), K_{\mathrm{a}}$ and $\left.K_{\mathrm{b}}\right)$ would reflect this varied composition and not that of the original pulp because the milled pulp surface is expected to be richer in cellulose and hemicellulose. Nevertheless, the above phenomena did not 


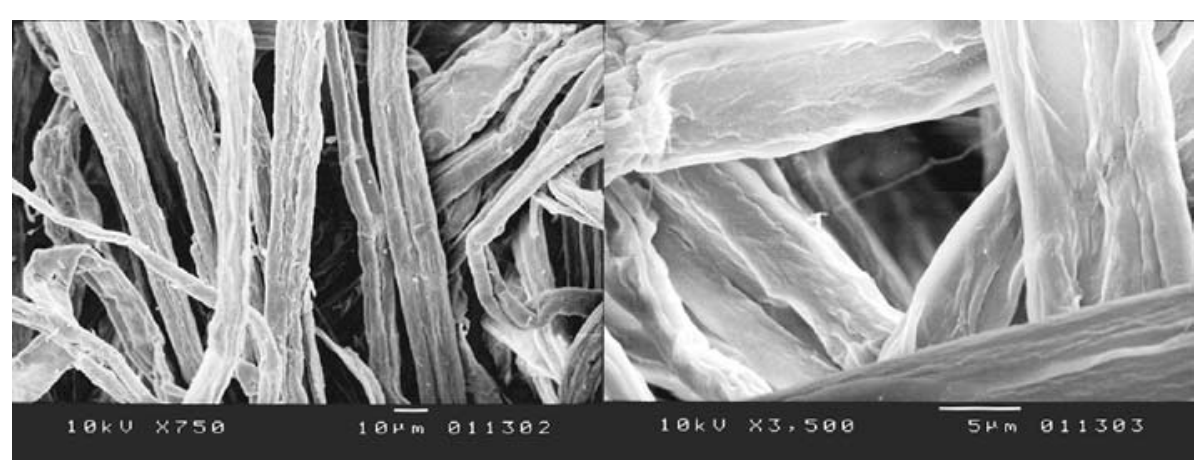

Figure 2. SEM images of the IGC stationary phase relating to sample A, at magnification levels of $750 \times$ (on the left) and $3500 \times$ (on the right).

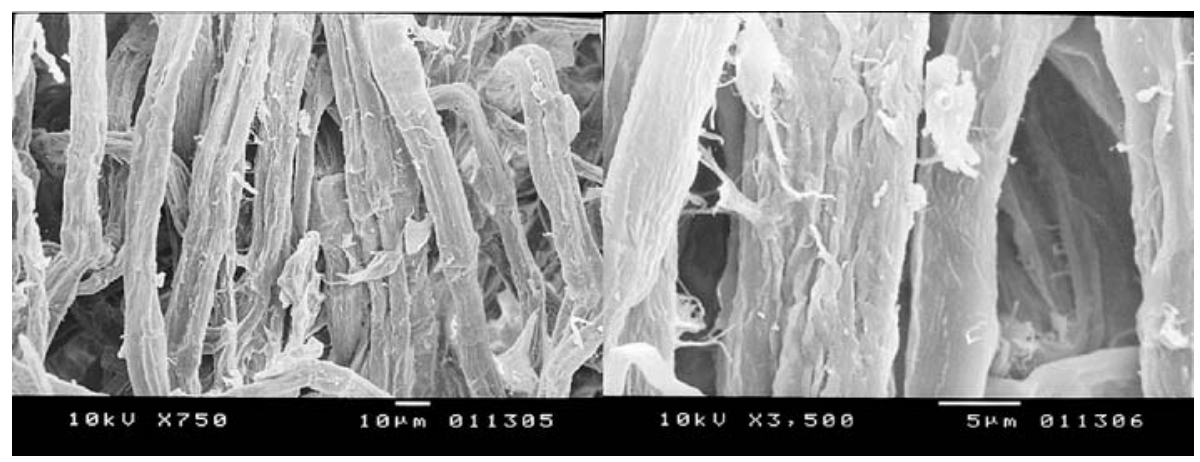

Figure 3. SEM images of the IGC stationary phase relating to sample B, at magnification levels of $750 \times$ (on the left) and $3500 \times($ on the right).

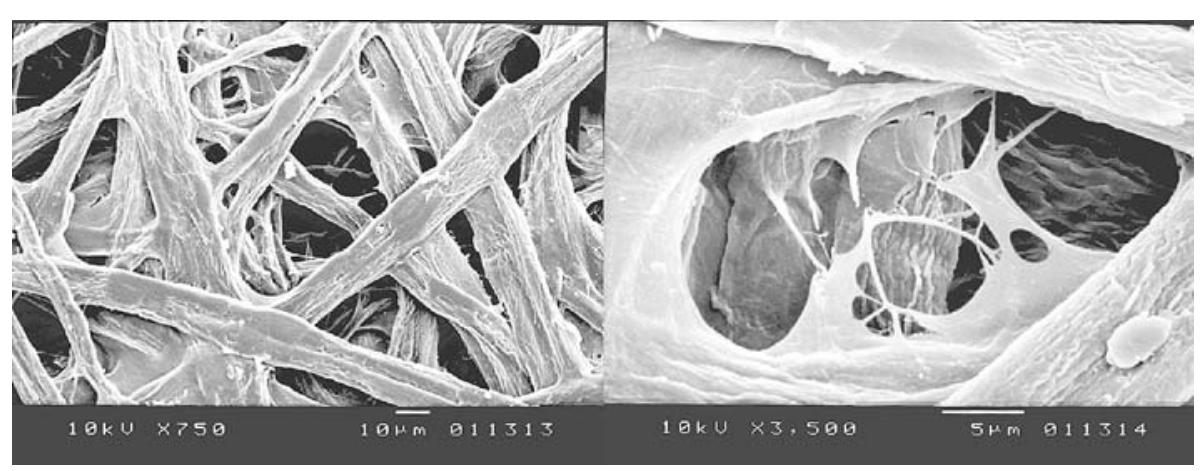

Figure 4. SEM images of the IGC stationary phase relating to sample C, at magnification levels of $750 \times$ (on the left) and $3500 \times($ on the right).

occur in the studied samples because of the gentle milling.

In addition, morphological differences are observed between sample B (beaten and milled pulp) and samples $C$ and $D$ (paper sheets made from beaten pulp), in particular the collapse of the surface fibre's and the presence of fines and colloidal material at the fibre's surface, due to the web-forming operation. The effects of these phenomena on the surface energetic properties will be discussed in detail further in this article. 


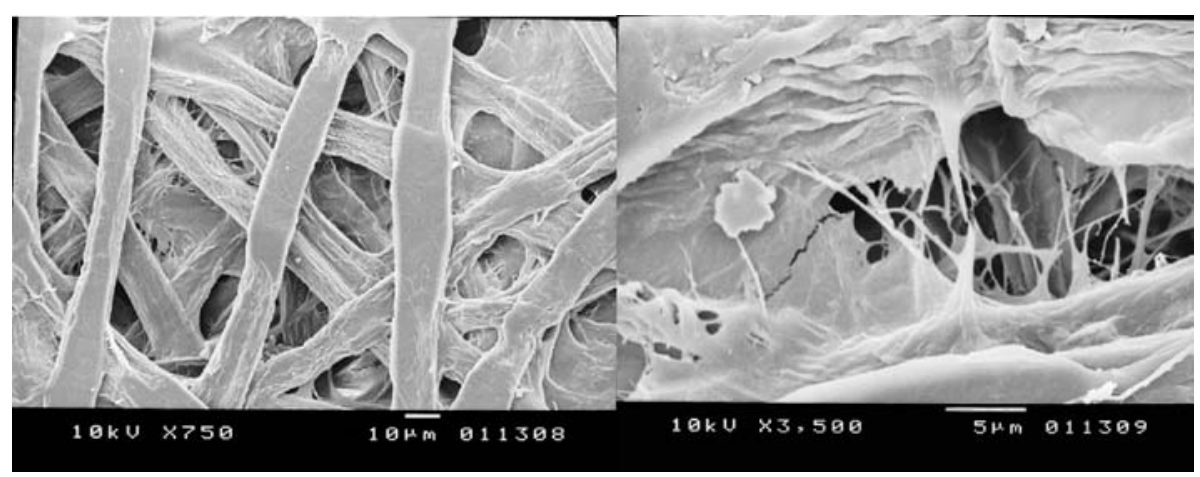

Figure 5. SEM images of the IGC stationary phase relating to sample D, at magnification levels of $750 \times$ (on the left) and $3500 \times($ on the right).

\section{Inverse gas chromatography}

The elution peaks obtained were generally symmetrical. For probe molecules that adsorb strongly on the stationary phase, such as THF, a tail was detected in the elution peak that did not influence the symmetry of the peak significantly as the magnitude of the tail was prominently lower than that of the elution peak. The presence of an asymmetrical peak would be due to the existence of dead volumes inside the IGC column or to significant surface energetic heterogeneity. In that situation, in order to account for the distribution of acidic/basic sites of various strengths, IGC under finite dilution conditions would be necessary. The Gaussian peaks observed indicate that the energetic heterogeneity is not significant, for any of the samples studied, under the operation conditions used for the IGC study. It should be mentioned that IGC carried out under infinite dilution conditions is more sensitive to the higher energy sites. IR spectroscopy was used in order to detect any contamination of the samples. No extraneous peaks, related with contaminants, were detected.

The retention times were not extrapolated to peaks of zero area as the volume of molecular probe injected in the IGC columns was residual and the IGC unit was set to the limit of probe detection by the FID detector. Typically, the syringe was filled with $1 \mu$ l of gaseous probe, flushed with air about 10 times, in order to ensure the creation of a Henry's infinite dilution region, and injected manually.

\section{Determination of the dispersive component of the surface tension}

The dispersive component of the surface tension, $\gamma_{\mathrm{s}}{ }^{\mathrm{d}}$ at $40^{\circ} \mathrm{C}$, determined according to Eq. (6), and its variation with temperature $\left(\mathrm{d} \gamma_{\mathrm{s}}^{\mathrm{d}} / \mathrm{d} T\right)$, are presented in Table 4. Figure 6 illustrates the dependence of $\gamma_{s}{ }^{d}$ on temperature, for all the samples analysed.

Although the modifications to which pulp A was subjected (beating, handsheet formation and sizing) greatly affect the sample surface energetic properties, all the values obtained for $\gamma_{\mathrm{s}}{ }^{\mathrm{d}}$ are consistent with those published in the literature for this type of materials (Belgacem 2000). A Whilelmy balance was used in an attempt to determine the contact angles for the fibres, but, due to their small length, it was not possible to prepare samples such that reliable results could be obtained. With regard to the handsheets, the sessile droplet method was used but the size of the pores, roughness and hydrophilicity of the surface did not allow for accurate results to be obtained in the

Table 4. Dispersive component of surface tension, $\gamma_{\mathrm{s}}{ }^{\mathrm{d}}$, and its variation with temperature for all the samples tested.

\begin{tabular}{|c|c|c|c|c|}
\hline & Sample A & Sample B & Sample C & Sample D \\
\hline $\begin{array}{l}\gamma_{\mathrm{s}}{ }^{\mathrm{d}}\left(\mathrm{mJ} / \mathrm{m}^{2}\right), 40{ }^{\circ} \mathrm{C} \\
\mathrm{d} \gamma_{\mathrm{s}}{ }^{\mathrm{d}} / \mathrm{d} T\left(\mathrm{~mJ} / \mathrm{m}^{2} \mathrm{~K}\right)\end{array}$ & $\begin{array}{l}45.0 \pm 0.38, r^{2}=0.995 \\
-1.06\end{array}$ & $\begin{array}{l}48.2 \pm 0.48, r^{2}=0.998 \\
-1.28\end{array}$ & $\begin{array}{l}31.3 \pm 0.02, r^{2}=1.000 \\
-0.61\end{array}$ & $\begin{array}{l}33.4 \pm 0.04, r^{2}=0.999 \\
-0.57\end{array}$ \\
\hline
\end{tabular}




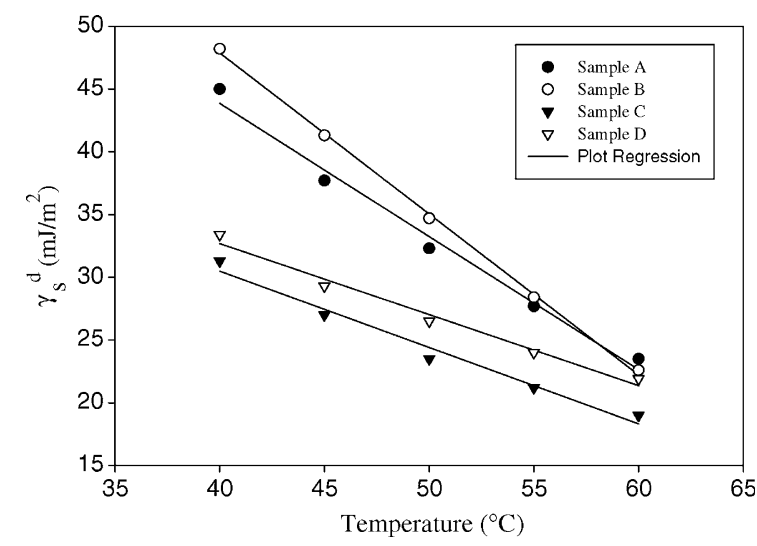

Figure 6. Variation of the dispersive component of surface tension with temperature for the various samples.

case of samples A, B and C. For sample D a value of $33.9 \mathrm{~mJ} / \mathrm{m}^{2}$ for $\gamma_{\mathrm{s}}{ }^{\mathrm{d}}$ and of $0.3 \mathrm{~mJ} / \mathrm{m}^{2}$ for $\gamma_{\mathrm{s}}{ }^{\mathrm{p}}$ were determined. Thus, the values of $\gamma_{\mathrm{s}}{ }^{\mathrm{d}}$ for sample D, obtained using IGC and the sessile droplet method, are in good agreement.

The increased exposed surface area, due to the production of fibrils and to the more open structure formed upon beating of the pulp (samples A and $\mathrm{B}$ ), is thought to result in increments in the amount of hydroxyl and carboxyl groups accessible at the surface and, thus, of bonding sites available for interaction with the IGC molecular probes. Consequently, the surface ability to establish dispersive interactions increases (higher $\left.\gamma_{\mathrm{s}}^{\mathrm{d}}\right)$. The dependence of $\gamma_{\mathrm{s}}{ }^{\mathrm{d}}$ on temperature (Figure 6) also increases for pulp B, denoting a higher entropic contribution to the surface free energy, a consequence of the greater mobility of molecular segments, namely fibrils, in the case of sample B.

The effect of web forming can be examined by comparing sample B (milled pulp) and sample C (pieces of handsheet). The latter shows a much lower value of the dispersive component of surface tension and of its temperature dependence (about half). This is most probably due to the enrichment of fines and colloidal material at the surface of the handsheets. Although the milling procedure, adopted in the case of samples A and B, could influence the surface properties of the pulp, as discussed earlier (it would contribute, for example, to the higher values of $\gamma_{s}{ }^{d}$ observed for samples A and $\mathrm{B}$ in comparison with those observed for samples $\mathrm{C}$ and $\mathrm{D}$ ), the web-forming operation is thought to be the major cause of the differences observed upon this operation, based on the SEM images (Figures 3-5) and on the IGC results (Figure 7 and Table 5). In Figures 4 and 5, it can be clearly seen that in samples C and D the presence of fines and colloidal material at the fibre's surface is very significant and, thus, these components are expected to influence very significantly the handsheet surface thermodynamic properties. Conversely, at the surface of the beaten pulp (sample B, Figure 3) no colloidal material can be identified (only the existence of fibrils originated from the beating process).

The differences in fines and extractives concentrations between the pulp and the handsheet fibres surface have been the subject of several studies. Three types of fines have been identified: primary fines, associated with the virgin pulp, secondary fines, produced during pulp processing prior to the forming operation, and tertiary fines, produced during the flow of non-retained stock around the paper machine white water system (Truong et al. 2003). Shen et al. (1998) and Truong et al. (2003) state that residual lignin and extractives of the fines fraction are present in a higher concentration (at the surface as well as in the bulk) than they are in the fibres fraction. Furthermore, the concentrations of lignin and residual extractives on the surface of the fibres are not the same as those in the bulk of the fibres, due to migration, resorption and reprecipitation phenomena (Shen and Parker 1999), during the cooking (Suurnakki et al. 1996) and the washing processes (Shen et al. 1998). Shen et al. (1998) have determined that the dispersive

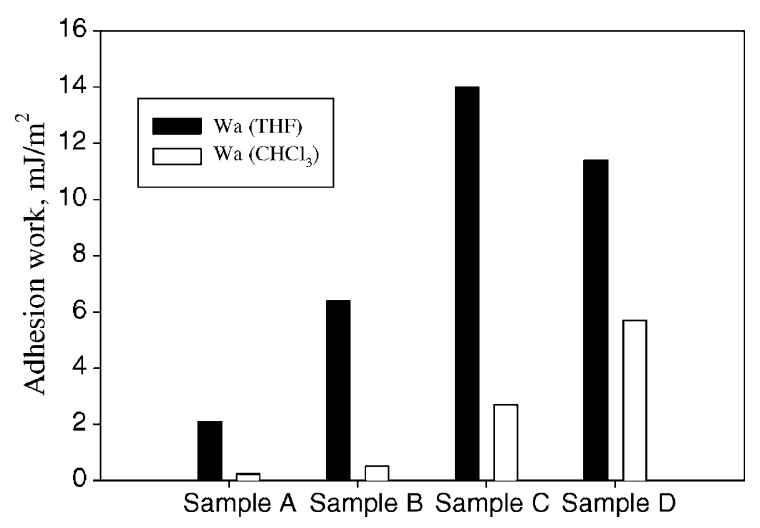

Figure 7. Specific component of the adhesion works for the basic (THF) and the acidic $\left(\mathrm{CHCl}_{3}\right)$ probes on the surfaces of samples $\mathrm{A}, \mathrm{B}, \mathrm{C}$ and $\mathrm{D}$, at $40^{\circ} \mathrm{C}$. 
Table 5. Ratios between the adhesion works $\left(W_{\mathrm{a}}^{\mathrm{s}}\right)$ and enthalpies of adsorption $\left(\Delta H^{\mathrm{s}}\right)$ of tetrahydrofuran and chloroform, and between the acidic and basic constants $\left(K_{\mathrm{a}}\right.$ and $K_{\mathrm{b}}$, respectively), relating to samples A, B, C and D.

\begin{tabular}{|c|c|c|c|c|}
\hline & Sample A & Sample B & Sample C & Sample D \\
\hline$W_{\mathrm{a}}^{\mathrm{s}}(\mathrm{THF}) / W_{\mathrm{a}}^{\mathrm{s}}\left(\mathrm{CHCl}_{3}\right), 40^{\circ} \mathrm{C}$ & 8.7 & 11.4 & 5.4 & 2.0 \\
\hline$\Delta H^{\mathrm{s}}(\mathrm{THF}) / \Delta H^{\mathrm{s}}\left(\mathrm{CHCl}_{3}\right)$ & 17.5 & 21.6 & 4.1 & 2.7 \\
\hline$K_{\mathrm{a}} / K_{\mathrm{b}}$ & 2.0 & 3.1 & 1.8 & 1.0 \\
\hline
\end{tabular}

component of the surface tension of the eucalypt fines is lower than that of the whole pulp (34.7 and $38.4 \mathrm{~mJ} / \mathrm{m}^{2}$, respectively). In another study, Shen and Parker (1999) found the values of 56.6 and $48.2 \mathrm{~mJ} / \mathrm{m}^{2}$ for cellulose and lignin, respectively. Other researchers have also found that lignin has a lower $\gamma_{\mathrm{s}}{ }^{\mathrm{d}}$ than cellulose (Belgacem 2000, Belgacem et al. 1995). Thus, it is concluded that the decrease observed in $\gamma_{\mathrm{s}}{ }^{\mathrm{d}}$ when the pulp is converted to handsheets is due to reprecipitation/migration of fines and colloidal material to the surface of the handsheet. This phenomenon would be caused by water flow during the web-forming process.

Regarding the influence of sizing, expressed by the differences between the results obtained for samples C and D, no significant change was detected for the surface free energy, despite other authors having reported a decrease in this parameter with sizing (Shen et al. 1998; Belgacem 2000). Possible explanations for this lack of literature agreement are the differences in both the type of sizing agent and procedure and the fact that, in this work, the effect of sizing was evaluated in handsheets instead of pulp fibres. Thus, the effect of sizing could be masked by the effect of web forming.

\section{Acid-base characteristics}

Although the discussion that follows is mainly based on the results obtained for THF (as a model basic probe) and $\mathrm{CHCl}_{3}$ (as a model acidic probe), the acidic/basic character of the samples was evaluated using all the polar probes referred to in Table 2, the results being consistent.

In Figure 7 are presented the values obtained for the specific component of the adhesion works of THF and of $\mathrm{CHCl}_{3}$ on the surface of all the samples analysed (derived from Eq. (8)). The values obtained for the specific component of the enthalpy of adsorption of THF and of $\mathrm{CHCl}_{3}$ (derived from Eq. (9)), and the values obtained for
$K_{\mathrm{a}}$ and $K_{\mathrm{b}}$ (calculated from Eq. (10)) are coherent with the tendencies observed in Figure 7. The relative values found for the specific component of the adhesion works and of the enthalpy of adsorption of THF and of $\mathrm{CHCl}_{3}$, as well as the relative values found for the acidic and basic constants $\left(K_{\mathrm{a}}\right.$ and $K_{\mathrm{b}}$, respectively) are presented in Table 5.

From the results presented in Table 5, namely the ratio $K_{\mathrm{a}} / K_{\mathrm{b}}$, it can be concluded that, excluding sample $\mathrm{D}$, all the samples have a predominant acidic character which decreases in the following order:

sample $\mathrm{B}>$ sample $\mathrm{A}>$ sample $\mathrm{C}>$ sample $\mathrm{D}$.

This tendency is corroborated by the values of the $W_{\mathrm{a}}^{\mathrm{s}}(\mathrm{THF}) / W_{\mathrm{a}}^{\mathrm{s}}\left(\mathrm{CHCl}_{3}\right)$ and $\Delta H^{s} \quad$ (THF) $/$ $\Delta H^{s}\left(\mathrm{CHCl}_{3}\right)$ ratios, revealing a good qualitative correlation between the three approaches.

From IGC experiments Shen et al. (1998) have shown that eucalypt pulp fibres are Lewis amphoteric with a strong acidic character. Our results are, thus, in agreement with expectation bearing in mind reports in literature and also the nature of cellulosic materials (extensive presence of $\mathrm{OH}$ and $\mathrm{COOH}$ functional groups).

As far as the beating effect is concerned, the increased $\mathrm{OH}$ and $\mathrm{COOH}$ groups concentration at the fibre's surface in the case of sample B (a consequence of the beating action as discussed above) results in increased works of adhesion with the polar probes, namely with the basic probe (thus reflecting a significant increase in the Lewis acidic character), Figure 7. The latter effect is also clear in Table 5. Here it can be observed that the presence of acidic sites relative to that of basic sites increases upon the beating operation.

As mentioned previously, the differences in surface energy upon web forming are thought to be due mainly to the increase in surface fines and colloidal material concentration. The primary fines have been shown to have a strong basic character, 
in an order of magnitude similar to that of cellulose (Shen and Parker 1999; Shen et al. 1998). On the other hand, lignin has a lower acidity than cellulose. In addition, Shen and Parker (1999) and Belgacem et al. (1995), showed that extraction of eucalypt fibres causes an increase of the works of adhesion with both acidic and basic probes. Our results (Figure 7, samples B and C), however, show that web forming increases the works of adhesion of both acidic and basic probes despite decreasing the relative acidity of the surface (Table 5). The greater concentration of fines observed in sample C (when compared to sample B) contributes indeed to the increase of the work of adhesion of the acidic probe (and to the decrease of the surface relative acidity). The discrepancy related to the basic probe may be justified by (1) the fact that lignin and extractives are not the only constituents of fines and colloidal material that also comprises carbohydrates, (2) the greater density of $\mathrm{COOH}$ and $\mathrm{OH}$ groups in the case of the fines and (3) the preferential orientation of these groups at the handsheet surface due to the web-forming operation conditions (towards the cellulosic surface used to absorb the water and to form the paper handsheet).

The last factor is important in many polymeric systems, as extensively illustrated by Schreiber et al. (1993). A good example is that of PMMA films prepared either by drying in air or by drying between plaques of different materials. When the PMMA film is dried in air, the methacrylate groups are oriented towards the bulk of the film, in order to minimize the PMMA film surface free energy (as the PMMA backbone is apolar). When the PMMA film is formed between two plaques of greater surface free energy (in this case metallic), the methacrylate groups are preferentially orientated towards the PMMA film/metallic plaque interface, thus minimizing the interface surface free energy. The result is a greater interaction capability of the PMMA film surface through specific (Lewis acid/base) forces. In the case of our samples, the pulp, after being thoroughly washed, is dried in air. On the other hand, the web-forming operation consists of placing wet handsheets between two plaques of high water absorbency paper, followed by application of pressure. Afterwards, the sheets are dried in air. The fact that the pulp is dried in air and the handsheet is formed between two cellulosic substrates would be expected to lead to differences in functional groups (hydroxyl and carboxyl groups) orientation at the surface, and, in particular, to increased Lewis acidic and basic character in the case of the handsheet. This reasoning must, nevertheless, be the subject of further experimental evidence.

The fines have a much larger specific surface area than the fibres and have been shown to have a much higher surface charge than the fibres, on a mass basis (Truong et al. 2003). When fines are removed, the eucalypt pulps studied by Truong et al. (2003) lose an average of $50 \%$ of their surface charge. The charge of the kraft pulp fibres and fines results from ionization mainly of carboxylic acid groups. The difference in $\mathrm{COOH}$ and $\mathrm{OH}$ functional groups per unit mass between the fines and the fibres can be explained by differences in size. Bearing in mind the typical dimensions of the fibres and of the primary fines, the surface charge of fines (and, thus, the $\mathrm{COOH}$ and $\mathrm{OH}$ functional groups concentration), can be estimated to be around 10 times that of the fibres. A practical evidence is that a large amount (50-75\%) of AKD sizing agent has been proven to be adsorbed by the fines in eucalypt pulps (Truong et al. 2003). Thus, the results obtained for the differences in the Lewis acid/base properties after web forming are thought to be due mainly to the higher concentration of fines (with higher charge density) in the handsheet surface.

It is clear from Figure 7 that the differences between the adhesion works of the acidic and the basic probes decreased from sample $\mathrm{C}$ to sample $\mathrm{D}$, due to sizing (that is, the surface of the sized handsheet is less Lewis acidic and more Lewis basic than the unsized sample). In addition, the ratio $K_{\mathrm{a}} /$ $K_{\mathrm{b}}$ not only decreased but is equal to unity for sample $\mathrm{D}$, denoting that sizing renders the sample more evenly bipolar. The loss of acidity and increased basicity with sizing is consistent with other studies reported elsewhere (Shen et al. 1998), and is likely to be related to the basic nature of AKD, which must have formed strong covalent bonds with the fibre's surface, decreasing the presence of acidic sites. It should be noted that the IGC results obtained in the present study do not indicate that sizing promotes wetting as (1) the AKD molecules form bonds with the fibres and, thus, decrease the sites for interaction with water or other molecules, and (2) the specific surface area (Table 3) decreases upon sizing and so does porosity (SEM imaging, 
Figures 4 and 5), thus, decreasing opportunity for sorption and spreading of liquids.

\section{Conclusions}

In this work, inverse gas chromatography was used to study the influence of beating, web forming and sizing on surface free energy of bleached Eucalyptus globulus kraft fibres. Milled pulps or pieces of handsheets were used as the stationary phase.

The results have shown that beating, although increasing only slightly the dispersive component of the surface tension, greatly enhances the acidic character of the fibres surface, probably due to a greater number of hydroxyl and carboxyl functional groups accessible at the fibre's surface. The specific surface area has increased as expected.

The process of web-forming decreases the specific surface area and causes the retention of fines and colloidal material at the surface of the fibres. Consequently, this operation greatly decreases the ability of forming dispersive intermolecular forces bonds, resulting in significantly lower values for $\gamma_{\mathrm{s}}{ }^{\mathrm{d}}$. Nevertheless, the specific (acidic/basic) intermolecular interactions with the polar probes greatly increase, probably due to increased hydroxyl and carboxyl functional group concentration and exposure at the papersheet surface (a consequence of the greater concentration of fines and colloidal material).

Because of the basicity of AKD and also due to the strong bonds formed between this sizing agent and the fibre surface, the availability of electronaccepting sites, relative to the electron donor sites, decreases and the surface of the sized handsheet becomes more Lewis basic.

Although internal sizing plays an important role in controlling liquid spreading at the paper surface and liquid penetration on the fibre's network, it is concluded that web forming is probably the papermaking operation that mostly contributes to the changes of the surface energetic properties of the cellulose fibres.

\section{Acknowledgements}

Thanks are due to Sapiens Program for the research grant (PE044-PE/PPQ/34159/99). The skilful work of Eng ${ }^{\mathrm{a}}$ A. Aquino in IGC analysis, Eng $^{\circ}$ V. Redondo in BET surface area determination, $\mathrm{Eng}^{\mathrm{O}}$ J.P. Dias in SEM imaging and Eng ${ }^{\mathrm{a}}$ M.J. Travassos in FTIR analysis is also acknowledged.

\section{References}

Al Saigh Z.Y. 1994. Recent advances in the characterisation of polymers and polymer blends using the inverse gas chromatography method. Polym. News 19: 269-279.

Aquino A.I., Ferreira P.J., Carvalho M.G., Amaral J.L. and Figueiredo M.M. 2002. Influence of cooking and bleaching conditions on the surface and paper properties of Eucalyptus globulus kraft pulps. Proceedings of the 2nd Iberoamerican Congress on Pulp and Paper Research, CD-ROM, CIADICYP, São Paulo, Brasil.

Banerjee R.K. 1991. Surface characterization of paper and printability. IPPTA - Indian Pulp \& Paper Technical Association Annual General Meeting \& Seminar on Developments in Pulp mill and Paper Machine Clothings, New Delhi, pp. 75-90.

Belgacem M.N. 2000. Characterization of polysaccharides, lignin and other woody components by inverse gas chromatography: a review. Cell. Chem. Technol. 34: 357-383.

Belgacem M.N., Czeremuszkin G. and Sapieha S. 1995. Surface characterization of cellulose fibres by XPS and inverse gas chromatography. Cellulose 2: 145-157.

Chtourou H., Riedl B. and Kokta B.J. 1995. Surface characterization of modified polyethylene pulp and wood pulp fibres using XPS and inverse gas chromatography. Adhes. Sci. Technol. 9(5): 551-574.

Dorris C.M. and Gray D.G. 1980. Adsorption of $n$-alkanes at zero surface coverage on cellulose paper and wood fibres. J. Colloid Interface 77(35): 353-362.

Fowkes F.M. 1987. Role of acid-base interfacial bonding in adhesion. J. Adhes. Sci. Technol. 1(1): 7-14.

Kamdem D.P. and Riedl B. 1992. Inverse gas chromatography of lignicellulosic fibres coated with a thermosetting polymer: use of peak maximum and Conder and Young methods. J. Colloid Interface Sci. 150: 507-516.

Kamdem D.P., Bose S.K. and Luner P. 1993. Inverse gas chromatography characterization of birch wood meal. Langmuir 9(11): 3039-3044.

Lee L.H. 1991. Relevance of the density-functional theory to acid-base interactions and adhesion in solids. In: Mittal K.L. and Anderson J. (eds), Acid-Base Interactions: Relevance to Adhesion Science and Technology. Utrecht, The Netherlands, pp. 25-46.

Lee H.L. and Luner P. 1989. Characterisation of AKD sized papers by inverse gas chromatography. Nordic Pulp Paper Res. J. 4: 164-172.

Mukhopadhyay P. and Schreiber H.P. 1993. Inverse gas chromatography for polymer surface characterization above and below Tg. Macromolecules 26: 6391-6396.

Papirer E. and Balard H. 1999. Inverse gas chromatography: a method for the evaluation of the interaction potential of solid surfaces. Surfact. Sci. Ser. 80: 145-171. 
Santos J.M.R.C.A., Gil M.H., Portugal A. and Guthrie J.T. 2001. Characterization of the surface of a cellulosic multipurpose office paper by inverse gas chromatography. Cellulose 8: 217-224.

Santos J.M.R.C.A., Fagelman K. and Guthrie J.T. 2002a. Characterisation of the surface Lewis acid/base properties of the components of pigmented, impact-modified, PC/PBT blends by inverse gas chromatography - phase separation and phase preference. J. Chromatogr. A 969(1-2): 119-132.

Santos J.M.R.C.A., Fagelman K. and Guthrie J.T. 2002b. Characterisation of the surface Lewis acid/base properties of poly(butylene terephthalate) by inverse gas chromatography. J. Chromatogr. A 969(1-2): 111-118.

Schreiber H.P. 1993. Aspects of component interactions in polymer systems. In: Akovali G. (ed.), The interfacial interactions in Polymeric composites. Kluwer Academic Publishers, The Netherlands, pp. 21-59.

Schultz J. and Lavielle L. 1989. Interfacial properties of carbon fiber-epoxy. In: Lloyd D.R., Ward T.C. and Schreiber H.P (eds), Inverse Gas Chromatography, Characterization of Polymers and Other Materials. A.C.S, Washington, pp. 185202.
Schultz J. and Lavielle L. 1989. Interfacial properties of carbon fiber-epoxy. In: Lloyd D.R., Ward T.C. and Schreiber H.P. (eds), Inverse Gas Chromatography, Characterization of Polymers and Other Materials. A.C.S, Washington, pp. 185202.Schultz J. and Lavielle L. 1989. Interfacial properties of carbon fiber-epoxy. In: Lloyd D.R., Ward T.C. and Schreiber H.P. (eds), Inverse Gas Chromatography, Characterization of Polymers and Other Materials. A.C.S, Washington, pp. 185-202.

Shen W., Yao W., Li M. and Parker I.H. 1998. Characterization of eucalypt fibre surface using inverse gas chromatography and X-ray photoelectron spectroscopy. Appita J. 51(2): 47-51.

Shen W. and Parker I.H. 1999. Surface composition and surface energetics of various eucalypt pulps. Cellulose 6: 41-55.

Suurnakki A., Heijnesson A., Buchert J., Viikari L. and Westermark U. 1996. Chemical characterisation of the surface layers of unbleached pine and birch kraft pulp fibers. J. Pulp Paper Sci. 22(2): 43-47.

Truong B.Y., Shen W. and Parker 2003. I Effect of primary fines and surface charge of hardwood pulps on AKD sizing. Appita J. 56(1): 30-34. 